\title{
The Effect of the Wear of Rotor Pins on Grinding Efficiency in a High-speed Disintegrator
}

\author{
Karel DVOŘÁK ${ }^{1}$ *, Dušan DOLÁK ${ }^{1}$, David PALOUŠEK ${ }^{2}$, Ladislav ČELKO $^{3}$, David JECH JE $^{3}$ \\ ${ }^{1}$ Institute of Technology of Building Materials and Components, Faculty of Civil Engineering, Brno University of \\ Technology, Veveři 331/95, 60200 Brno, Czech Republic \\ ${ }^{2}$ Department of Reverse Engineering and Additive Technologies, Faculty of Mechanical Engineering, Brno University of \\ Technology, Technická 2896/2, 61669 Brno, Czech Republic \\ ${ }^{3}$ Central European Institute of Technology, Brno University of Technology (CEITEC - BUT), Brno, Czech Republic
}

crossref http://dx.doi.org/10.5755/j01.ms.24.1.17737

Received 10 March 2017; accepted 19 June 2017

\begin{abstract}
One of the directions intensively investigated in the field of milling is high-energy milling (HEM). One type of HEM is high-speed grinding in high-speed disintegrators. This type of mill is particularly suitable for the grinding and activation of fine powder materials. It has several advantages, such as a very intensive and continual refining process. One disadvantage is that its grinding pins are prone to abrasion, which may result in a decrease of the efficiency of grinding. This effect was investigated in this paper. Laboratory high speed disintegrator DESI 11 with steel pins was used. Portland clinker was chosen for the experiment, because of its average hardness. After each kilogram of the milled material, a sample was taken and the weight loss of the rotors was measured. The wear of the rotors was also measured using the 3D optical scanner ATOS Triple Scan. Results show that wear of rotors has a significant impact on the grinding efficiency. Keywords: high-speed grinding, disintegrator, wear, abrasion.
\end{abstract}

\section{INTRODUCTION}

High-energy milling (HEM) is one of the trends in the field of milling that have recently been subject to intensive study. Mechanochemical activation phenomena have been observed in this kind of milling technology [1,2]. The effects of mechanical activation have been described for model materials such as dolomite [3] or clay minerals [4, 5], or, for example, for silica [6] and for recycled concrete [7]. The widest areas of HEM use are in various fields of metallurgy [8-11], and in the preparation of various intermetallic and ceramic materials [12], and nanomaterials [13]. One type of HEM is high-speed grinding (HSG). HSG mills effectively deliver high amounts of energy to the material. One of the types of mills suitable for HSG is a high-speed pin mill with two counter-rotating rotors, known as a disintegrator [14]. The principle of a disintegrator lies in bringing the material to a high speed by means of the pins on the grinding rotors. The material is refined by very dramatic changes in mechanical stress with very high frequency. Due to this principle, this mill is particularly suitable for the grinding and activation of fine powder materials [15]. Disintegration of the material in this type of pin mill can be described by several fundamental milling mechanisms. These are an impact, impact and shear, shear (attrition) and tension/bending. There are also other processes taking place, which are similar to those in attritors or jet mills. Not only impacts of particles on the pins but also mutual collisions among the particles can be expected. They are caused by turbulent flow and rapid compression and expansion between the rotors [16,17]. Another advantage, apart from the very fast continual grinding process, is the variety of working tools that can be employed to affect the grinding process [1]. However, this type of HSG disintegrator has two important disadvantages. The first one is the significant electrostatic charging of the particles and their easy and quick aggregation [1]. Another and most important disadvantage is the grinding elements' susceptibility to abrasion. If the pins are damaged due to abrasion, the grinding efficiency could be reduced. The intensity of wear depends on the mineralogy, morphology and granulometry of the material being ground and of course on the quality of the material, which the mill chamber and milling elements are made from [18]. Based on the results of Misra and Finie [19], Larsen-Badse [20] and the authors' previous research [21], very fine Portland cement with a specific surface of $400 \mathrm{~m}^{2} / \mathrm{kg}$ according to Blaine was used in this experiment for the assessment of wear effect on grinding efficiency. Currently, HSG is not used in the cement industry. However, this material is very well described [22]; it is abrasive enough, due to its hardness between $6-7$ according to the Mohs scale, and its fineness is well measurable by the simple standardised Blaine air permeability method [23]. The material of the mill was, in this case, less important because it can be assumed the harder material will only prolong the erosion process. Nevertheless, changes in the pins' shape will have the same eventual effect on grinding efficiency [24].

\section{MATERIALS AND METHODS}

The first step was the preparation of Portland cement. It was prepared from two components at the ratio of $95 \mathrm{wt} \%$ of Portland clinker to $5 \mathrm{wt} . \%$ of gypsum PREGIPS. Both

\footnotetext{
* Corresponding author. Tel. +420 541147511; fax: +420 541147501.

E-mail address: dvorak.k@fce.vutbr.cz.(K. Dvořák)
} 
components were dosed into the laboratory ball mill OM BRIO 20 and milled to the specific surface area of $400 \mathrm{~m}^{2} / \mathrm{kg}$ according to Blaine [23]. This value of specific surface is usual in the case of industrially manufactured Portland cements CEM I 42,5 R. The mill rotation frequency was $45 \mathrm{rpm}$ at a total dose of $5 \mathrm{~kg}$. The chemical composition was determined according to EN 196-2 standard [25]. The mineralogical composition was analysed by X-Ray powder diffraction; an XRD Panalytical Empyrean device was used in this case. Density was determined by a Micromeritics AccuPyc II 1340 automatic pycnometer. For the measurement of Blaine specific surface area, a PC-Blaine-Star automatic device was used with a measurement cell capacity of 7.95 cubic centimetres. The determination was performed three times to eliminate errors, and the resultant value was an average calculated from these determinations. A laser granulometry device, Malvern Mastersizer 2000, was used for the measurement of the middle grain size. The experiment assessing the effect of the wear of rotor pins on grinding efficiency was carried out in a DESI 11 disintegrator, which is a high-speed pin mill with two counter-rotating rotors. The total installed power of this mill is $4.1 \mathrm{~kW}$. The rotors' rotation frequency is up to $12000 \mathrm{rpm}$, and the maximum speed of impact is $240 \mathrm{~ms}^{-1}$. The material is delivered by a continuous feeder and enters the grinding chamber through the middle of the left rotor. The feeding speed was $2 \mathrm{~kg}$ per minute, which is maximum capacity. The construction of the mill allows for a choice of working tools. For this experiment, CR type rotors were used. The rotors were designed and manufactured by the company FF servis s.r.o. The left rotor has two rows of pins and the right rotor has three rows. The pins are cubic. Both rotors were made from steel.

Before the milling started, both rotors were measured using a 3D optical scanner ATOS Triple Scan, GOM $\mathrm{GmbH}$, Germany. The principle of this scanner is based on active fringe projection. The ATOS Triple Scan allows the measuring of a wide variety object sizes by changing the lenses of the CCD cameras and projector and the angle between the cameras. The accuracy of the optics and the scanner was verified for the lenses used by the producer according to "VDI/VDE 2634, Part 3 - Optical 3Dmeasuring systems, multiple view systems based on area scanning". A programmable rotary table was used for the measurement. Evaluation of the scanned data was performed in the ATOS Professional software. The measurements in this study were made with MV170 lenses $(170 \times 130 \times 130 \mathrm{~mm})$, calibrated for a small object arrangement. The measuring point distance is $0.055 \mathrm{~mm}$, i.e. 18 points $/ \mathrm{mm}$, the recommended reference point diameter is $0.8 \mathrm{~mm}$, measuring distance $490 \mathrm{~mm}$, camera angle $28^{\circ}$, the focal length of the camera lenses $40 \mathrm{~mm}$ and focal length of the projector lens $60 \mathrm{~mm}$. Before 3D digitisation, the scanner with the MV170 set of lenses was calibrated. The process of calibration consisted of a set of scans of the calibration object from different distances and angles. 3D digitising of the geometry was performed using a 3D optical scanner and a two-axis rotary table controlled by a software script. Software evaluation of the volumes was performed in the ATOS Professional 3D measurement and inspection software. The scans of the new rotors were taken as reference. Next, both rotors were weighed. The abrasion of the milling elements was evaluated by recording the weight loss of the rotors after the passage of $1,3,5,10$ and $15 \mathrm{~kg}$ of material. Also, the impact of rotor wear on grinding efficiency was measured by monitoring the increase in the specific surface area of the milled cement and by the influence on the middle size of the grains. After that, $15 \mathrm{~kg}$ of cement was milled and a 3D scan of the worn rotors was taken and compared with the reference. The reference part and the sanded part were placed through the "plane-linepoint" alignment principle to the same position. All pins were cut off in software by one plane and all bottom boundaries were closed to create a watertight mesh. Both rotors were processed the same way. Based on the 3D digital data the volumes of the meshes were evaluated. This data was used for the calculation of mass loss of the pins and compared with the reduction in the increase of the cement specific surface area.

\section{RESULTS}

The results of the chemical composition tests of the laboratory-made Portland cement are shown below in Table 1. Only selected oxides and loss on ignition are listed in the table.

Table 1. The chemical composition of the Portland cement

\begin{tabular}{|c|c|c|c|c|c|c|c|}
\hline Comp. & $\mathrm{SiO}_{2}$ & $\mathrm{Al}_{2} \mathrm{O}_{3}$ & $\mathrm{Fe}_{2} \mathrm{O}_{3}$ & $\mathrm{CaO}$ & $\mathrm{SO}_{3}$ & LoI & Others \\
\hline $\begin{array}{c}\text { Cont., } \\
\%\end{array}$ & 19.28 & 4.95 & 4.79 & 63.69 & 3.08 & 1.05 & 3.17 \\
\hline
\end{tabular}

The chemical composition was typical for Portland cement. The mineralogical composition measured by XRD was also typical for alitic Portland cement. The main cement phases, alite, betite Brownmillerite and tricalcium aluminate, were identified. The weighted average hardness of the Portland cement minerals is $6-7$ according to the Mohs scale [22].

The density and specific surface area of the laboratorymade Portland cement after homogenization and milling of both components in a laboratory ball mill OM-BRIO 20 are listed in Table 2.

Table 2. Density and specific surface area of the laboratory-made Portland cement

\begin{tabular}{|c|c|}
\hline Density, $\mathrm{kg} / \mathrm{m}^{3}$ & 3105 \\
\hline Specific surface area, $\mathrm{m}^{2} / \mathrm{kg}$ & 403 \\
\hline
\end{tabular}

The density was very close to the theoretical value of $3100 \mathrm{~kg} / \mathrm{m}^{3}$ mentioned in literature [22]. The abrasion process of both rotors is demonstrated by the changes in the rotors' weight in Table 3 and Table 4.

Table 3. Weight changes in both rotors

\begin{tabular}{|c|c|c|c|c|c|c|}
\hline \multirow{2}{*}{$\begin{array}{c}\text { Rotor } \\
\text { weight }\end{array}$} & \multicolumn{5}{|c|}{ Mass of the cement passed through the HSG mill } \\
\cline { 2 - 7 } & $0 \mathrm{~kg}$ & $1 \mathrm{~kg}$ & $3 \mathrm{~kg}$ & $5 \mathrm{~kg}$ & $10 \mathrm{~kg}$ & $15 \mathrm{~kg}$ \\
\hline $\begin{array}{c}2 \text { rows of } \\
\text { pins, g }\end{array}$ & 171.7 & 170.6 & 169.6 & 168.4 & 165.6 & 163.6 \\
\hline $\begin{array}{c}3 \text { rows of } \\
\text { pins, g }\end{array}$ & 214.6 & 214.0 & 213.4 & 212.7 & 211.1 & 210.3 \\
\hline
\end{tabular}


Table 4. Weight loss in both rotors in grams and percent

\begin{tabular}{|c|c|c|c|c|c|c|}
\hline \multirow{2}{*}{$\begin{array}{c}\text { Rotor } \\
\text { weight }\end{array}$} & \multicolumn{5}{|c|}{ Mass of the cement passed through the HSG mill } \\
\cline { 2 - 7 } & $0 \mathrm{~kg}$ & $1 \mathrm{~kg}$ & $3 \mathrm{~kg}$ & $5 \mathrm{~kg}$ & $10 \mathrm{~kg}$ & $15 \mathrm{~kg}$ \\
\hline $\begin{array}{c}2 \text { rows of } \\
\text { pins, } \mathrm{g}\end{array}$ & 0.0 & 1.09 & 2.13 & 3.28 & 6.14 & 8.06 \\
\hline $\begin{array}{c}3 \text { rows of } \\
\text { pins, } \mathrm{g}\end{array}$ & 0.0 & 0.56 & 1.23 & 1.90 & 3.48 & 4.34 \\
\hline $\begin{array}{c}2 \text { rows of } \\
\text { pins, \% }\end{array}$ & 0.0 & 0.64 & 1.24 & 1.91 & 3.57 & 4.70 \\
\hline $\begin{array}{c}3 \text { rows of } \\
\text { pins, \% }\end{array}$ & 0.0 & 0.26 & 0.57 & 0.89 & 1.62 & 2.02 \\
\hline
\end{tabular}

The results indicate a decrease in the weight of both rotors. Visually, wear was observed on the pins, but not on the bearing ring. The rotor with two rows, which is on the inlet side of the mill, was worn far more severely. Its weight loss was almost double than that of the other rotor. The impact on the efficiency of grinding is notable, as seen in Table 5.

Table 5. Reduction of the increase of cement specific surface area

\begin{tabular}{|c|c|c|c|c|c|c|}
\hline \multicolumn{7}{|c|}{ Mass of the cement passed through the HSG mill } \\
\hline \multicolumn{2}{|c|}{$0 \mathrm{~kg}$} & $1 \mathrm{~kg}$ & $3 \mathrm{~kg}$ & $5 \mathrm{~kg}$ & $10 \mathrm{~kg}$ & $15 \mathrm{~kg}$ \\
\hline $\begin{array}{c}\text { Spec. surf., } \\
\mathrm{m}^{2} / \mathrm{kg}\end{array}$ & 403 & 466 & 461 & 456 & 441 & 432 \\
\hline $\begin{array}{c}\text { Increase of } \\
\text { spec. surf., } \\
\mathrm{m}^{2} / \mathrm{kg}\end{array}$ & - & 63 & 58 & 53 & 38 & 29 \\
\hline $\begin{array}{c}\text { Reduction } \\
\text { of increase, } \\
\%\end{array}$ & - & 0.00 & 7.94 & 15.87 & 39.68 & 53.97 \\
\hline
\end{tabular}

The results show a significant decrease in the increment of the specific surface area with increasing wear of the rotors. After $15 \mathrm{~kg}$ of material pass-through, the increase in specific surface area was only $50 \%$ of the initial value. The results of the specific surface area are, for better illustration, compared with the loss on both rotors, see Fig. 1. Besides the basically linear decrease in the increment of specific surface area, the growth of medium value of the particle size was also observed, see Fig 2.

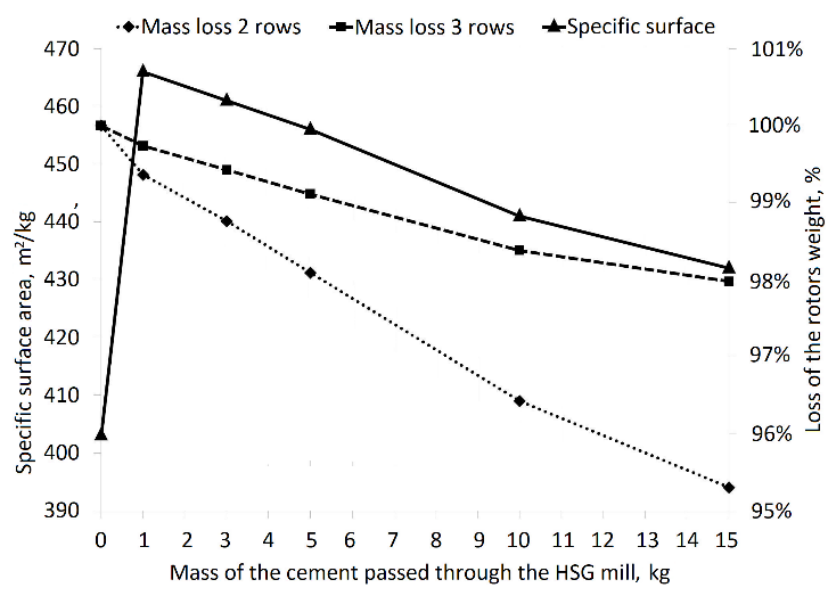

Fig. 1. Specific surface area, loss of rotor weight

The total weight decrease of $2 \%$ (in the case of the 3 -row rotor) and $5 \%$ (in the case of the 2 -row rotor) does not seem too significant. However, the reducing effect on the efficiency of grinding is considerable.

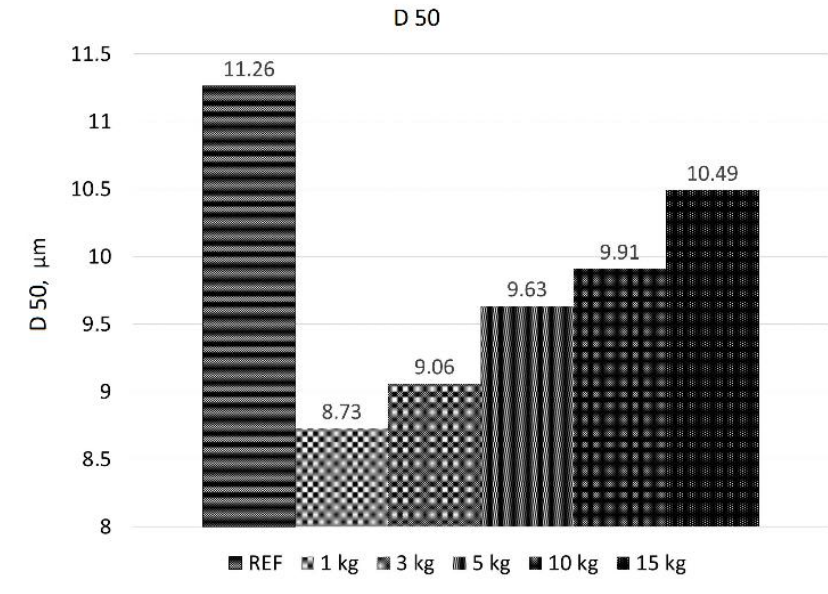

Fig. 2. Laser granulometry - increase of D 50

Because the most worn parts of rotors were the pins, which represent only a small amount of material, a 3D scan of both rotors was made before and after grinding. The results of the scanning and subsequent modifications are shown in Fig. 3 and Fig. 4 for the new and worn rotor respectively. A two pin rotor was chosen as representative.

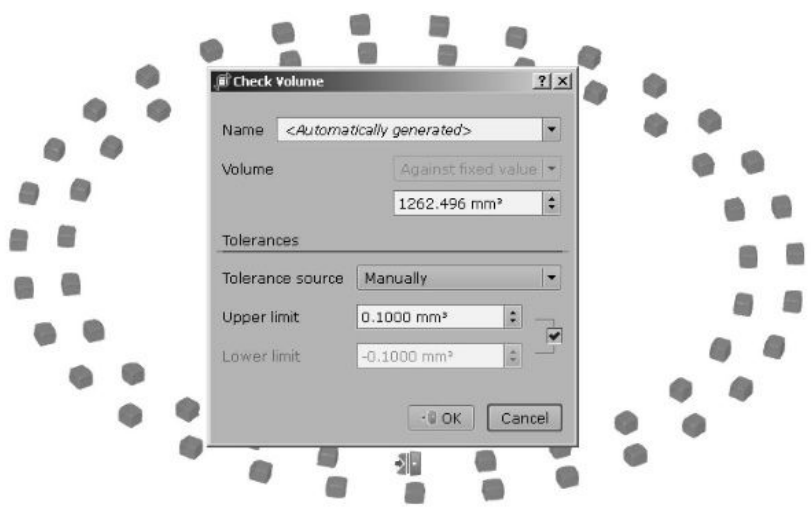

Fig. 3. Scan and volume measurement, reference 2-row rotor

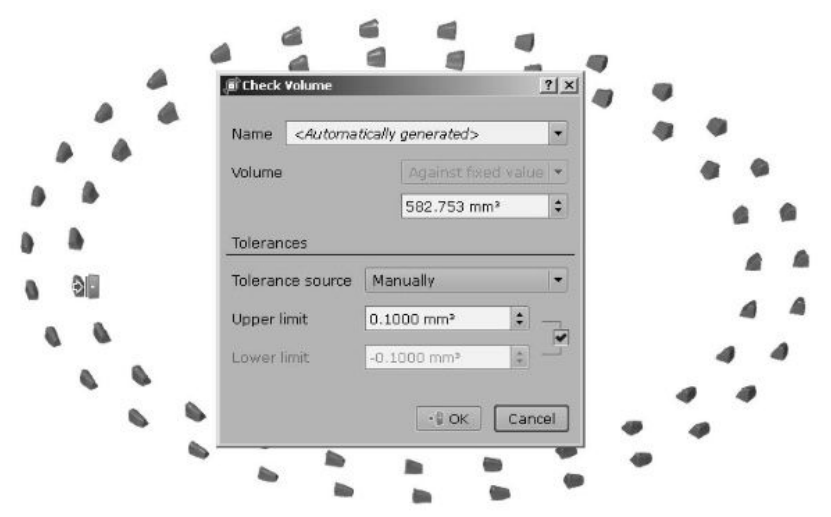

Fig. 4. Scan and volume measurement, worn 2-row rotor

The superposition of both scans clearly shows the wear of the rotors. Change in the pins' shape is notable. The originally cubic pins were worn mainly on the front and lower side, i.e. in locations where there is constant contact with ground material. The superposition of the scans before and after grinding and the effect on the pin shape is clearly visible in Fig. 5 and Fig. 6. 


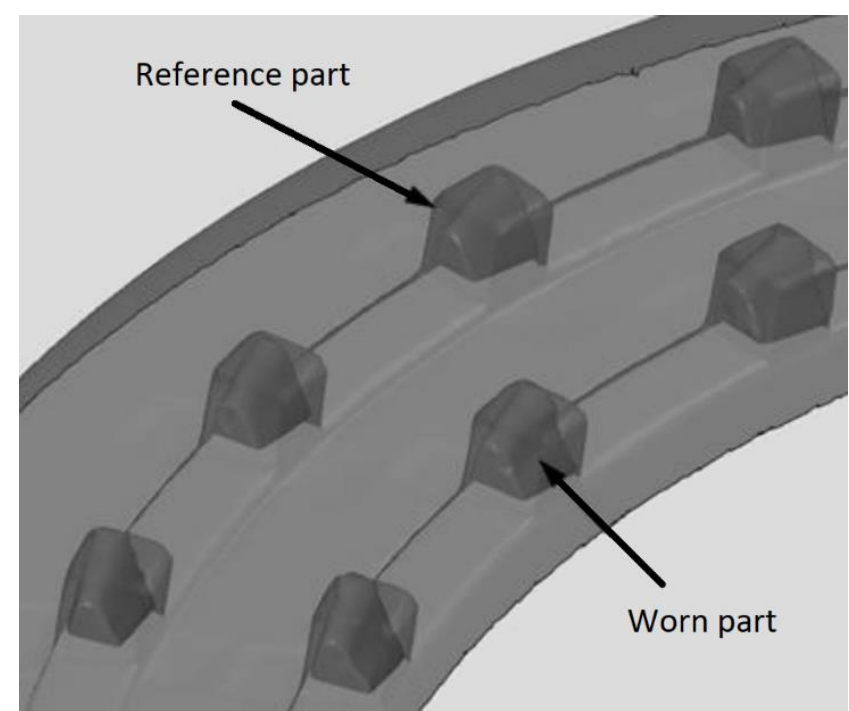

Fig. 5. Superposition of the reference and worn rotors

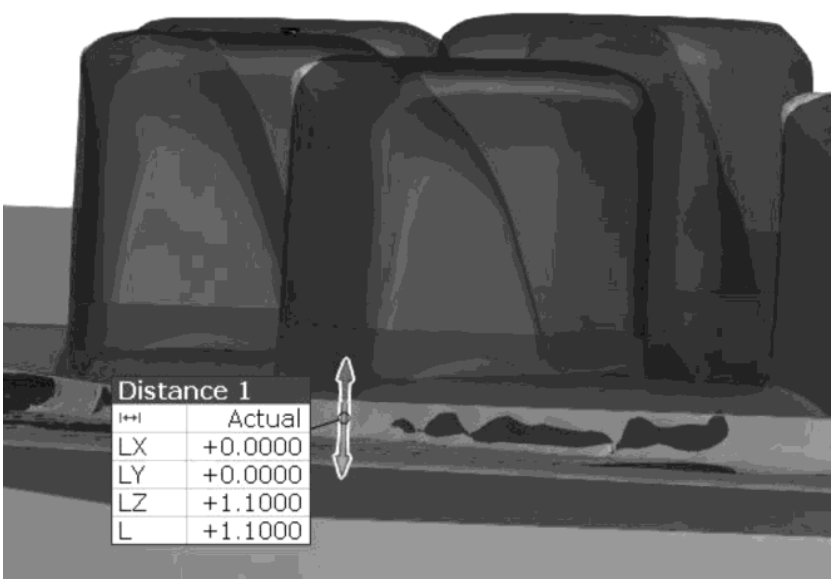

Fig. 6. Superposition of the reference and worn rotors in details

The volume of the pins was calculated from the $3 \mathrm{D}$ data. The mass of material attributable to the pins was calculated from the density of steel of $7850 \mathrm{~kg} / \mathrm{m}^{3}$. Results of the volume, weight and especially reduction in the weight and volume of the pins after grinding of $15 \mathrm{~kg}$ of the material is presented in Table 6.

Table 6. Volume, weight and weight reduction of the pins after milling of $15 \mathrm{~kg}$ of cement

\begin{tabular}{|c|c|c|c|c|c|c|}
\hline Rotors & $\begin{array}{c}\text { Ref., } \\
\mathrm{mm}^{3}\end{array}$ & $\begin{array}{c}\text { Worn, } \\
\mathrm{mm}^{3}\end{array}$ & Ref., g & $\begin{array}{c}\text { Worn, } \\
\mathrm{g}\end{array}$ & $\begin{array}{c}\text { Reduc., } \\
\mathrm{g}\end{array}$ & $\begin{array}{c}\text { Reduc., } \\
\%\end{array}$ \\
\hline 2 rows & 1263 & 583 & 9.91 & 4.58 & 5.34 & 54 \\
\hline 3 rows & 1768 & 1406 & 13.88 & 11.04 & 2.84 & 11 \\
\hline
\end{tabular}

Again, 2-row rotors were significantly more worn than 3 -row ones. Results show more than $50 \%$ reduction in the mass of 2 -row rotors after grinding.

The values of weight loss calculated from the 3D scan and the measured weight loss of the rotors were used in calculating the weight loss ratio between the bearing ring and pins. Results show that for both $2-$ and 3 -row rotors, weight loss attributed to pins is approximately $66 \%$, as seen in Fig. 7. This value was then used to calculate the approximate wear of the pins in percentage for milling 1 to $10 \mathrm{~kg}$ of cement. The results are presented in Table 7.
Table 7. Pins mass reduction - calculated

\begin{tabular}{|l|c|c|c|c|c|}
\hline \multirow{2}{*}{ Rotors } & \multicolumn{5}{|c|}{ Pins mass reduction - calculated, \% } \\
\cline { 2 - 6 } & $1 \mathrm{~kg}$ & $3 \mathrm{~kg}$ & $5 \mathrm{~kg}$ & $10 \mathrm{~kg}$ & $15 \mathrm{~kg}$ \\
\hline 2 rows & 7.3 & 14.2 & 21.9 & 41.0 & 53.8 \\
\hline 3 rows & 2.6 & 5.8 & 9.0 & 16.4 & 20.5 \\
\hline
\end{tabular}
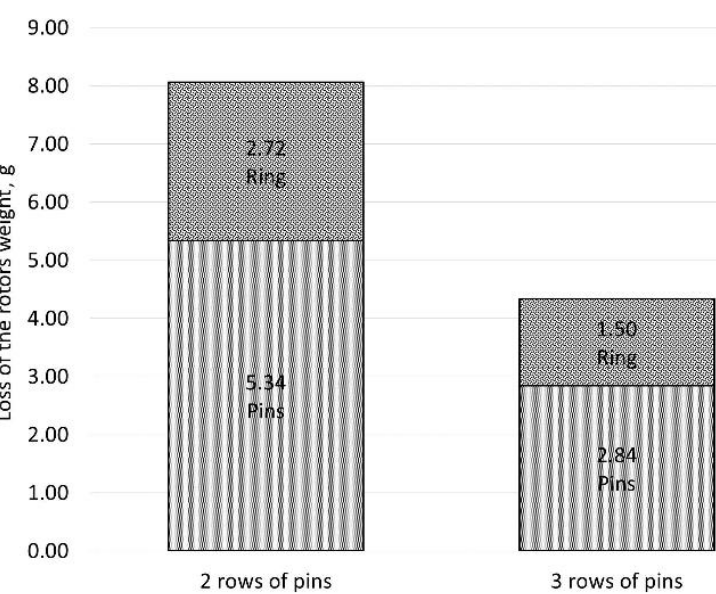

3 rows of pins

Fig. 7. Weight loss ratio between pins and rings

The final impact of pin wear on grinding efficiency is summarised in the graph below, see Fig. 8.

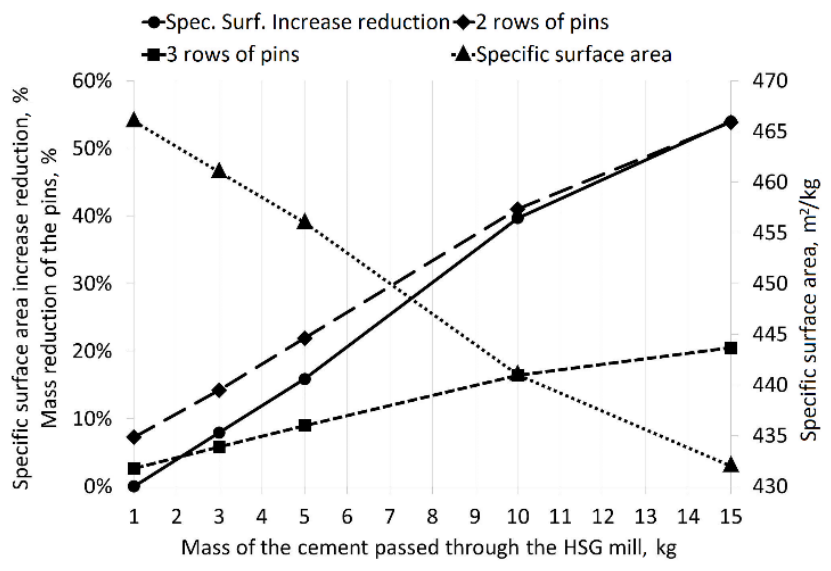

Fig. 8. Effects of the wear of rotor pins on grinding efficiency

\section{DISCUSSION}

The chemical and mineralogical composition of the cement was typical for average Portland cement and could be used for the experimental assessment of the effect of the wear on the efficiency of milling in an HSG disintegrator. The abrasion was first assessed visually. In particular, the abrasion of the pins was observed during grinding. Abrasion of the rotor supporting ring was minimal. The weight loss of the two-row rotor was significantly higher, about $50 \%$ more than in the case of the three-row rotor. This disproportion can be explained by the construction of the disintegrator. Material enters into the milling chamber through the central part of the mill on the side where the two-row rotor is fixed. The first contact it makes is the first row of pins on the threerow rotor. These pins propel the material in the opposite direction to that the first row of pins on the two-row rotor is moving. It is these pins that perform the bulk of the grinding as the particles impact their front faces. Therefore, they are being intensively eroded due to the very high velocity of the 
impacting particles. The same situation is repeated between the second row on the three-row rotor and the second row on the two-row rotor. Nevertheless, this theory should be verified by mathematical modelling for example by the discrete elements method. The reduction of the increase of cement's specific surface area was considerable with increasing wear of the rotors, $16 \%$ after milling of $5 \mathrm{~kg}$, $40 \%$ after $10 \mathrm{~kg}$ and $54 \%$ after $15 \mathrm{~kg}$. The decrease of the cement specific surface area was essentially linear but with a tendency to slow down when the two-row rotors pins were eroded enough. Moreover, what was interesting, the wear rate of the three-row rotors was decreasing while the wear of the two-row rotor was increasing. The results indicate that if the specific surface area of the input cement is $400 \mathrm{~m}^{2} / \mathrm{kg}$, more grinding occurs due to impacts on the front faces of the rotor pins than by turbulent flow and mutual collisions among the particles. This phenomenon is mainly visible on the pins on the two-row rotor $[16,17]$.

In order to differentiate and better describe the rotor abrasion, the method of 3D optical laser scanning was used. This method made possible to separate and describe abrasion of the pins themselves. From the results is clear that the pins on the two-row rotor were highly eroded; up to $54 \%$ of their original mass after milling of $15 \mathrm{~kg}$ of cement. The shape of the pins of this rotor became more aerodynamic. This is in contrast with the three-row rotors pins. These pins were eroded only to $20 \%$ and still kept the original cubic shape. The results obtained by measurement of the pin volume by this 3D scanning method corresponded with the weight loss measurement very well. Based on the results of both types of measurement, it was found that the wear of pins represents $66 \%$ of the whole rotor wear. There were no differences between 2 -row and 3-row rotors. It was possible to calculate the approximate pin mass reduction for the other phases of milling by recalculating the pin volume to weight loss.

Finally, it can be stated that the wear of pins, mainly of the pins of the two-row rotor, has a significant effect on milling efficiency. The increase of cement specific surface area was reduced by approximately $50 \%$ while the reduction of the two-row rotors pin mass was $50 \%$. When the front face of the pin is worn to an "aerodynamic" shape, the impacts of the particles against pin are less frequent. Therefore, grinding of the particles is likely happening due to a mutual collision in the turbulent zone behind the pins. Nevertheless, this zone is also reduced because of the pin abrasion. This has the effect of reducing the efficiency of grinding and thus causes an increase of the specific surface area. Furthermore, it seems the pins on the three-row rotor are loaded less compared with those on the two-row rotor and their abrasion is slower thereby also contributing less to the work being performed.

\section{CONCLUSION}

High-speed grinding in a high-speed disintegrator is very fast and effective but the susceptibility of pins to wear is a real disadvantage. This is especially true in the case of hard materials. Due to rotor abrasion, the efficiency of the milling process rapidly decreases. The increment of cement specific surface area decreased to approximately $50 \%$ very fast in the case of the HSG disintegrator DESI 11, which is representative of pin mils with two counter-rotating rotors. This mill is equipped with two different rotors. One has two rows of pins and is fixed on the inlet side of the mill and the other has three rows of pins and is fixed on the opposite side. The grinding efficiency reduction relates to the wear of the two-row rotors pins more than to the wear of the three-row rotor. When the decrease of the increment of the specific surface area reached $50 \%$, the mass loss ratio between tworow rotors and the three-row rotor pins reached 2.7:1. Moreover, the final shape of the pins of the two-row rotor was aerodynamic as opposed to the shape of the three-row rotor pins which were still close to their original cubic shape. Based on these results, it seems the pins on the opposite three-row rotor are less stressed compared with the two-row rotor and their abrasion is slower. However, they also contribute less to the grinding work being performed. Also, in this type of HSG mill with the CR type of rotors with cubic pins, grinding occurs more due to impacts on front faces of the rotor pins than by turbulent flow and mutual collisions among particles.

\section{Acknowledgments}

This work was financially supported by project No. LO1408 "AdMaS UP", and project No. LO1202 "MEYS" both supported by the Ministry of Education, Youth and Sports under "National Sustainability Programme I" and by project No. 15-08755S: "Study of the effects of samples preparation on the final properties of inorganic binders".

\section{REFERENCES}

1. Baláž, P. Mechanochemistry in Nanoscience and Minerals Engineering. Springer-Verlag Berlin Heidelberg, 2008. https://doi.org/10.1007/978-3-540-74855-7

2. Massalimov, I.A. Materials Processing in a Disintegrator and their Use for the Improvement of Chemical Technologies. Abstract of doctoral thesis, Ufa, 2005. http://www.ogbus.ru/authors/Massalimov/Massalimov_1.pdf

3. Tkáčková, K. Mechanical Activation of Minerals Minerals Engineering 11 (4) 1991: pp. 185-187.

4. Vdovic, N., Jurina, I., Skapin, S.D., Sondi, I. The Surface Properties of Clay Minerals Modified by Intensive Dry Milling-Revisited Applied Clay Science 48 (4) 2010: pp. $575-580$. https://doi.org/10.1016/j.clay.2010.03.006

5. Hrachova, J., Komadel, P., Fajnor, V.S. The Effect of Mechanical Treatment on the Structure of Montmorillonite Materials Letters 61 (16) 2007: pp. 3361-3365. https://doi.org/10.1016/j.matlet.2006.11.063

6. Kotake, N., Kuboki, M., Kiya, S., Kandac, Y. Influence of Dry and Wet Grinding Conditions on Fineness and Shape of Particle Size Distribution of Product in a Ball Mill Advanced Powder Technology 22 (1) 2011: pp. 86-92. https://doi.org/10.1016/j.apt.2010.03.015

7. Bumanis, G., Bajare, D. Compressive Strength of Cement Mortar Affected by Sand Microfiller Obtained with Collision Milling in Disintegrator Procedia Engineering 172 2017: pp. 149-156. https://doi.org/10.1016/j.proeng.2017.02.037

8. Hueler, M., Chernik, G.G., Fokina, E.L., Budim, N.I. Mechanical Alloying in Planetary Mills of High 
Accelerations Reviews on Advanced Materials Science 18 (4) 2008: pp. 366-374.

9. Razavi, T.S., Yazdani, R.R., Salahi, E., Mobasherpour, I., Razavi, M. Production of $\mathrm{Al}-20$ wt. $\% \mathrm{Al}_{2} \mathrm{O}_{3}$ Composite Powder Using High Energy Milling Powder Technology 192 (3) 2009: pp. 346-351.

https://doi.org/10.1016/j.powtec.2009.01.016

10. Wang, X., Zigang, Z. Sintering and Properties of Ultrafine Binderless WC Advances in Powder Metallurgy \& Particulate Materials 8 2009: pp. 6-11.

11. Muroi, M., Street, R., McCormick, P.G. Structural and Magnetic Properties of Ultrafine La0.7Ca0.3MnO2 Powders Prepared by Mechanical Alloying Journal of Solid State Chemistry 152 (2) 2000: pp. 503-510. https://doi.org/10.1006/jssc.2000.8719

12. Serena, S., Caballero, A., Turrillas, $X$., Martin, D., Sainz, M.A. Effect of Ceramic Nanoparticles on the SolidState Reaction Mechanism of Dolomite-Zirconium Oxide Followed by Neutron Thermodiffraction Measurements Journal of Nanoparticle Research 11 (4) 2009: pp. $869-878$.

https://doi.org/10.1007/s11051-008-9466-0

13. Rojac, T., Kosec, M., Malic, B., Holc, J. Mechanochemical Synthesis of NaNbO3 Materials Research Bulletin 40 (2) 2005: pp. 341-345.

https://doi.org/10.1016/j.materresbull.2004.10.018

14. Hint, J.A. The Basic Problems of Mechanical Activation Reports of the 5th Symposium on Mechanochemistry and Mechanics of Hard Materials 1977: pp. 14-32.

15. Kipnis, B.M. Analysis of Prospects for the UDD-Technology in the Field of Polymeric Materials UDD-Technology Abstracts II, SKTB 1983: pp. 44-46.
16. Janalík, J. Obtékání a odpor těles, Ediční středisko VŠB TU Ostrava, 1. vydání, 2008.

http://www.338.vsb.cz/PDF/Janalik-Obtekani.pdf

17. Kovalev, P.I. Influence of Shock Destruction of Solid and Liquid Particles in the Supersonic Flow Around a Solid Two-Phase Flow Journal of Applied Physics 78 (1) 2008: pp. 40-46.

18. Gahlin, R., Jacobson, S. The Particle Size Effect in Abrasion Studied by Controlled Abrasive Surfaces Wear 224 1999: pp. $118-125$. https://doi.org/10.1016/S0043-1648(98)00344-5

19. Misra, A., Finnie, I. On the Size Effect in Abrasive and Erosive Wear Wear 65 (3) 1981: pp. 359-373. https://doi.org/10.1016/0043-1648(81)90062-4

20. Larsen-Badse, J. Influence of Grit Diameter and Specimen Size on Wear During Sliding Abrasion Wear $12(1)$ 1968: pp. $35-53$. https://doi.org/10.1016/0043-1648(68)90574-7

21. Dvořák, K., Dobrovolný, P., Gazdič, D. Effect of Input Granulometry of Cement on the Milling Process in a HighSpeed Disintegrator Powder Metallurgy and Metal Ceramics 2017: (In press)

22. Hewlett, P.C. Lea's Chemistry of Cement and Concrete $4^{\text {th }}$ edition. Elsevier, 2003.

23. ČSN EN 196-6:2010 Methods of testing cement - Part 6: Determination of Fineness.

24. Kulu, P., Hussainova, I., Veinthal, R. Solid Particle Erosion of Thermal Sprayed Coatings Wear 258 2005: pp. $488-496$. https://doi.org/10.1016/j.wear.2004.03.021

25. ČSN EN 196-2:2013 Method of testing cement. Chemical analysis of cement. 